\title{
Sequential surgical resection of hepatic and pulmonary metastases from colorectal cancer
}

\author{
Stefan Limmer • Elisabeth Oevermann • \\ Claudia Killaitis • Peter Kujath • Martin Hoffmann • \\ Hans-Peter Bruch
}

Received: 30 November 2009 / Accepted: 13 January 2010/Published online: 18 February 2010

(C) The Author(s) 2010. This article is published with open access at Springerlink.com

\begin{abstract}
Background Resection of isolated hepatic or pulmonary metastases from colorectal cancer is widely accepted and associated with a 5 -year survival rate of $25-40 \%$. The value of aggressive surgical management in patients with both hepatic and pulmonary metastases still remains a controversial area.

Materials and methods A retrospective review of 1,497 patients with colorectal carcinoma (CRC) was analysed. Of 73 patients identified with resection of $\mathrm{CRC}$ and, at some point in time, both liver and lung metastases, 17 patients underwent metastasectomy (resection group). The remaining 56 patients comprised the non-resection group. Primary tumour, hepatic and pulmonary metastases of all patients were surgically treated in our department of surgery, and the results are that of a single institution.

Results The resection group had a 3-year survival of $77 \%$, a 5 -year survival of $55 \%$ and a 10 -year survival of $18 \%$; median survival was 98 months. The longest overall survival was 136 months; six patients are still alive. In the resection group, overall survival was significantly higher than in the non-resection group $(p<0.01)$. Independent from the chronology of metastasectomy, 5-year survival was $55 \%$ with respect to the primary resection, $28 \%$ with respect to the first metastasectomy and $14 \%$ with respect to
\end{abstract}

This paper was presented at the 126th Annual Meeting of the German Society of Surgery, Munich, Germany, April 28th-May 1st, 2009.

S. Limmer $(\bowtie) \cdot$ E. Oevermann · C. Killaitis · P. Kujath •

M. Hoffmann · H.-P. Bruch

Department of Surgery,

University Hospital of Schleswig-Holstein,

Campus Luebeck, Ratzeburger Allee 160,

23538 Luebeck, Germany

e-mail: stefan.limmer@uk-sh.de the second metastasectomy. A disease-free interval ( $>18$ months), stage III (UICC) and age ( $<70$ years) were found to be significant prognostic factors for overall survival.

Conclusion Our report strongly supports aggressive surgical therapy in patients with both hepatic and pulmonary metastases from CRC. Overall survival for surgically treated selected patients with both hepatic and pulmonary metastases from CRC is comparable to hepatic or pulmonary metastasectomy. Simultaneous metastases tend to have a poorer outcome than metachronous metastases.

Keywords Colorectal cancer · Lung metastases . Hepatic metastases $\cdot$ Metastasectomy

\section{Introduction}

Second to lung cancer in men and breast cancer in women, colorectal carcinoma (CRC) has increased in incidence over the past 20 years. About half of the patients undergoing radical resection of CRC will develop metastatic disease [1, 2], mostly to the liver (33\%) and the lungs (22\%) [3]. The overall 5-year survival rate of potentially radical resected CRC has been estimated to $71 \%$ [4]. Patients with untreated metastatic CRC have a poor outcome with a 5-year probability of survival of $<5 \%$ [5]. Conventional management of metastatic CRC has been directed at palliation. But chemotherapy-based treatment regime seldom produced long-term survival in these patients. These disappointing results have led to the general acceptance of surgical treatment of patients with metastatic disease to the liver or to the lung. Nowadays, resection of hepatic metastases has become an effective treatment with a reported 5-year survival of $39 \%$ [6]. Likewise, the resection of lung 
metastases has a 5 -year probability of survival ranging from $21 \%$ to $43 \%$ [7-9]. The discouraging results of chemotherapy along with the encouraging survival rates in resected patients have led to the attempts to expand the indication for surgical treatment of metastatic CRC in patients with metastases both to the liver and to the lung. Several reports from other institutions showed a survival rate of these highly selected patients similar to patients who underwent surgical resection of metastases confined only to the lung [10-12]. However, the results are limited by a small number of patients.

We reviewed the characteristics of our patients with radical (R0) resection in an attempt to evaluate the efficacy of resection of both hepatic and pulmonary metastases.

\section{Materials and methods}

A retrospective single-centre data analysis of all patients with R0 resected hepatic and pulmonary metastases of colorectal cancer was performed. The study period ranged from January 1990 to February 2008. All patients with radical (R0) resected CRC and synchronous or metachronous hepatic and pulmonary metastases were included. Selection criteria for resection of the metastatic lesion were a controlled primary tumour and controlled or controllable lesions.

Preoperative staging included coloscopy with histopathological biopsy, endoscopic ultrasound and CT scan of abdomen and chest. Postoperative staging of CRC was classified according to the UICC (Union internationale contre le cancer) guidelines [13]. Surgical data and histopathological findings were evaluated retrospectively. Follow-up data were obtained through a standardised surveillance programme for colorectal cancer including coloscopy, liver ultrasonography, chest radiography and determination of carcinoembryonic antigen (CEA) level. In the case of a suspected lesion or elevated CEA level, further diagnostic imaging (CT scan, PET) was added. Surgery was indicated in all cases of newly detected pulmonary or hepatic lesions.

By definition, metastases occurring within 3 months after resection of the primary tumour were termed synchronous metastases. In contrast, metastases that occurred after a disease-free interval of more than 3 months after primary resection were termed metachronous.

Liver resections were classified as solitary or multiple wedge resections, lobectomy, segmentectomy or hemihepatectomy. Additional hyperthermic or radiofrequency ablation in combination with liver resection was also assessed. Pulmonary resections were classified as wedge resection, segmentectomy or laser ablation. Bilateral lung metastases or recurrent lesions were not a contraindication. The medical records of all patients with pulmonary and hepatic metastases of colorectal cancer were reviewed with regards to age, sex, disease-free interval, mortality, morbidity and survival. Postoperative mortality was defined as any death that occurred within 30 days after either lung or liver resection or during the same period of hospitalisation.

\section{Statistics}

Statistical analysis was performed with SPSS 17.0 (SPSS Inc., Chicago, IL, USA). The significance of relations between patient groups and pathological parameters were analysed using Pearson's chi-square or Fisher's exact test. Survival analysis was performed using Kaplan-Meier [14] (for univariate analysis) and Cox regression model (multivariable model) with the date of the primary tumour resection as the starting point. Survival curves were compared using the log-rank test. A two-sided $p<0.05$ was considered significant.

\section{Results}

Between January 1990 and February 2008, a total of 1,497 patients underwent radical (R0) surgical resection of colorectal cancer at the Department of Surgery, University of Schleswig-Holstein, Campus Luebeck. Among these, 177 patients developed metastases confined to the liver (39 synchronous, 138 metachronous), and 68 patients had undergone resection of pulmonary metastases (three synchronous, 65 metachronous).

Seventy-three patients developed both hepatic and pulmonary metastases (17 synchronous, 56 metachronous). Fortyfive patients were surgically treated (R0) in the first place. The remaining 27 patients were not surgically treated due to the following reasons: Seven patients had a diffuse metastatic spread of both liver and lung, three had multiple lesions in the liver (one with an additional carcinoma of the colon, ten local recurrences combined with metastases to the liver or the lung and seven patients with simultaneous metastatic occurrence in liver, lung and a third localisation (bone, brain, lymph nodes). These patients were treated by chemotherapy (CTX), radiotherapy (RTX), immunotherapy (ITX) or a combination. They had no surgical treatment at all.

When the tumour occurred in a further, second location, only 17 of these 45 patients could receive radical surgical treatment, whilst in the remaining 28 patients, a nonsurgical treatment (radiotherapy, chemotherapy, immunotherapy or any combination) was performed due to reduced general condition or multiloculary recurrence.

Of the highly selected group of patients with both hepato-pulmonary metastases, only a small number of 17 patients with both $\mathrm{R} 0$ resected metastases of $\mathrm{CRC}$ were identified in our retrospective study (Fig. 1). 
Fig. 1 Workflow description of all patients with $\mathrm{R} 0$ resected metastases of CRC $(n=17)$

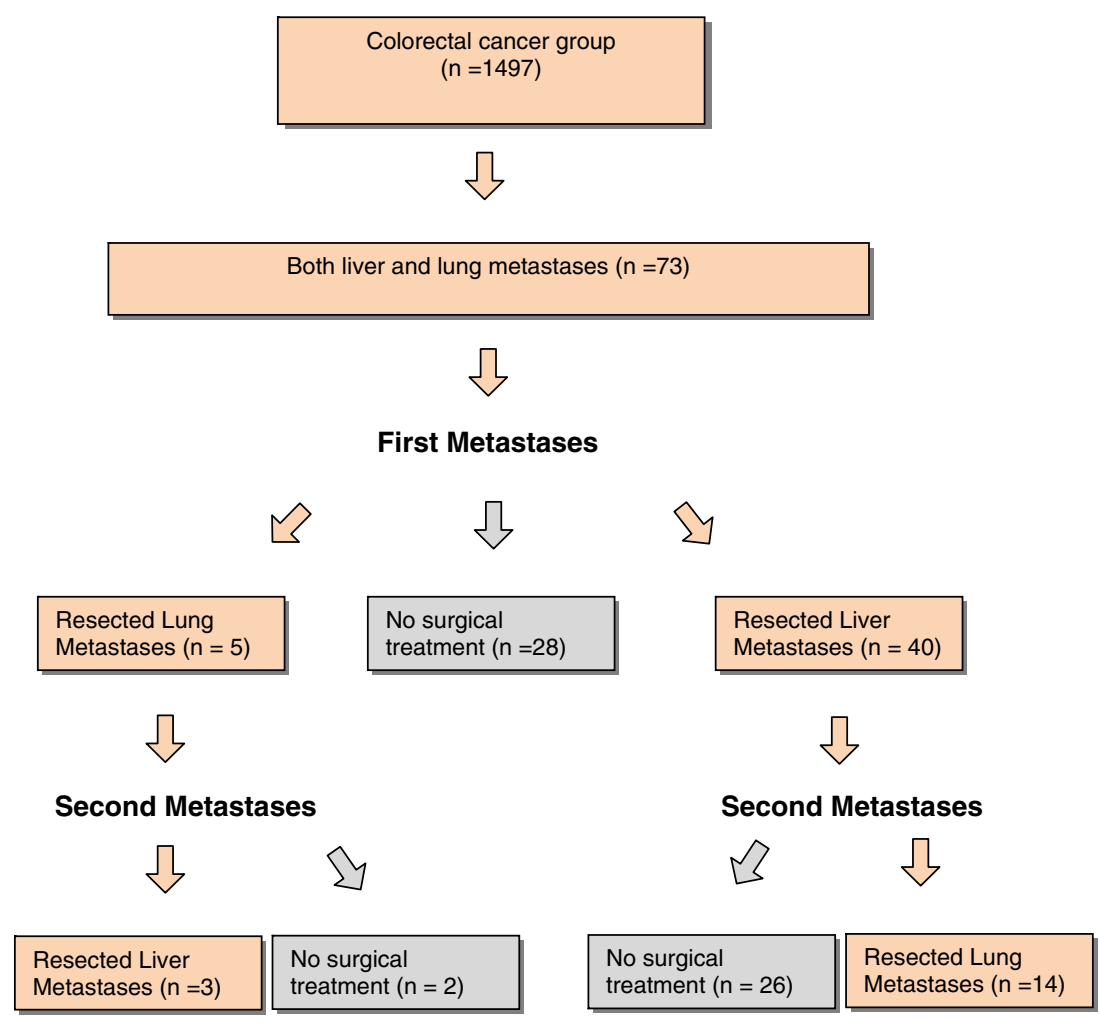

Nine of 73 patients had received neoadjuvant treatment (seven patients with combined chemo-radiotherapy, two patients only radiotherapy). Average overall survival (OS) in this group was 56.2 months ( $\mathrm{SD} \pm 11.4$ ), median 46.8 months. Two patients were still alive at the end of the study (range 23.1-133.3 months). Adjuvant treatment after colorectal resection was performed in 50 of 73 patients $(68.3 \%)$. There was no significant improvement of overall survival in patients with adjuvant chemotherapy versus patients with adjuvant chemo-radiotherapy (Table 1).

Fifty-one out of 73 patients underwent adjuvant treatment after metastasectomy (29 chemotherapy, two radiotherapy, 20 chemo-radiotherapy). Adjuvant therapy after first metastasectomy was not observed to improve longtime survival. Additional resection for recurrent disease was performed in two patients; both patients are alive with no evidence of disease (Table 2).
The R0 resection group had a better outcome than the non-resection/one-time resection group $(n=56)$ with a median survival of 97.8 versus 35.3 months. The difference in survival was found to be significant ( $p=0.009$; Fig. 2).

There were 11 men and six women, with a mean age of 58 years (range $42-72$ years) at the time of primary tumour resection. The primary site of the tumour was the colon in nine patients and the rectum in eight patients. All patients had initial R0 colorectal resection. In 15 patients, the tumour was resected by laparotomy; in two patients, a laparoscopic-assisted resection was performed (Sigma, Coecum).

On initial presentation, three patients had UICC classification stage I disease (18\%), two patients stage II $(12 \%)$, four patients stage III $(23 \%)$ and eight patients stage IV (47\%). Three patients received a neoadjuvant radiochemotherapy before their initial colorectal resection (rectal cancer

Table 1 Overall survival: adjuvant treatment after primary resection $(n=73)$

\begin{tabular}{|c|c|c|c|c|c|}
\hline & Number & Percentage & Mean survival $[ \pm( \pm \mathrm{SD})$ (months) & Median survival $( \pm \mathrm{SD})$ (months) & Significance (log rank) \\
\hline CTX & 28 & 38.3 & $56.1 \pm 7.4$ & $43.2 \pm 9.8$ & 0.27 \\
\hline RTX & 1 & 1.4 & $80.8 \pm 0.0$ & - & - \\
\hline RCTX & 21 & 28.8 & $41.9 \pm 4.4$ & $35.4 \pm 9.0$ & 0.9 \\
\hline CTX versus RCTX & & & & & 0.18 \\
\hline No Therapy & 23 & 31.7 & $46.2 \pm 7.3$ & $41.5 \pm 2.8$ & \\
\hline
\end{tabular}


Table 2 Overall survival: adjuvant treatment after metastasectomy $(n=73)$

\begin{tabular}{lccccc}
\hline & Number & Percentage & Mean survival $[ \pm( \pm \mathrm{SD})($ months $)$ & Median survival $( \pm \mathrm{SD})(\mathrm{months})$ & Significance $(\log$ rank) \\
\hline CTX (curative) & 33 & 45.2 & $56.3 \pm 5.6$ & $51.5 \pm 5.3$ & 0.98 \\
CTX (palliative) & 26 & 35.6 & $39.5 \pm 5.5$ & $27.7 \pm 1.8$ & 0.2 \\
RTX & 2 & 2.7 & $26.5 \pm 3.6$ & 22.9 & 0.01 \\
RCTX & 2 & 2.7 & $59.0 \pm 16.7$ & 35.4 & 0.51 \\
Immunotherapy & 2 & 2.7 & $63.4 \pm 21.5$ & 41.9 & 0.75 \\
No therapy & 8 & 11.0 & $58.5 \pm 13.9$ & $47.9 \pm 6.4$ & \\
\hline
\end{tabular}

stages III and IV). Ten patients (59\%) had adjuvant 5-FUbased chemotherapy after resection. Adjuvant chemotherapy after colorectal resection was given in seven of our patients $(41 \%)$. All of them received additional chemotherapy after resection of the first metastases. Two patients with stage II rectal cancer were given neoadjuvant radiochemotherapy; one of them received additional chemotherapy after resection of the primary tumour and after the resection of the metastases as well (Table 3). The overall survival in this patient was only 32 months. No patient had an intraabdominal recurrence. All patients showed a normal colonic endoscopic examination before liver or lung surgery.

Eight patients had synchronous metastases (six liver, two lung) and were all resected within 3 months after primary resection; nine patients developed metachronous metastases.

Median age at the time of liver resection was 74 years (range 46-78 years), and median time from colorectal resection to liver metastases was 1 year (range 0-6 years). There were 14 segmentectomies, four hepatectomies, two liver wedge resections and three additional hyperthermic

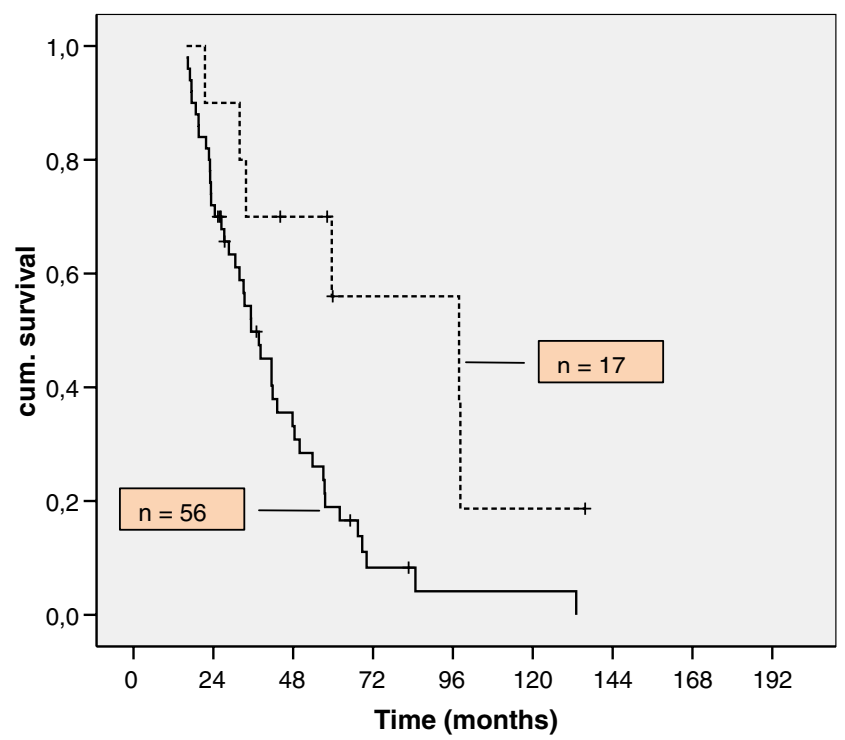

Fig. 2 Survival of patients with resected liver and lung metastases (dotted line) versus the non-surgical group (solid line) ablations performed. The average number of liver metastases per resection was 2.5 (range 1-10).

Median time at the age of lung resection was 59 years (range 42-74 years). Median time from colorectal resection to lung metastases was 2.5 years (range $0-6.8$ years). Two patients underwent repeat pulmonary resections for recurrent disease.

Fifteen patients underwent thoracotomy for resection of metastases; two patients were resected by thoracoscopy. One segmentectomy, 22 wedge resections and 39 laser resections were performed. The average number of lung metastases per resection was 4.6 (range 1-20; Table 4). After initial metastasectomy, the lung was the site of recurrence $(n=8 /$ $72.7 \%)$, followed by the liver $(n=3 / 27.3 \%)$.

No postoperative mortality was observed. Follow-up was complete in all patients and ranged from 21 to 136 months, with a median of 54 months. Mean disease-free interval (DFI) after resection of primary tumour was 14.1 months (range 0-72, median 10.8 months). DFI after first metastasectomy was 19.4 months (range 1.3-44.1, median 19.2 months). There was a significant impact of DFI on OS. A disease-free interval longer than 18 months was associated with an OS of 68.2 months (standard error 7.9, 95\% confidence interval), whilst patients with a DFI < 18 months after colorectal resection had an OS of 39.3 Monaten (SD 3.6, 95\% CI; $p=0.001$, log rank; Fig. 3). We also analysed patient survival according to tumour stage (UICC) as determined during surgery for CRC: Patients with stage I disease had a median survival of 98 months, stage II 33 months, stage III 62 months and 59 months in stage IV. Median survival in patients with primary CRC grades 1, 2 and 3 was 62,47 and 98 months, respectively.

Overall, 3-, 5- and 10-year survival after primary resection for patients with both hepatic and pulmonary metastases (resection group) was $77 \%, 55 \%$ and $18 \%$; median survival was 98 months (Table 5 and Fig. 4). Median OS of patients with R0 resected lung metastases of CRC was 59 months; patients with resected hepatic lesions had a median OS of 47 months. Median survival after first metastatic resection was 47.7 months (range 10.0-117.4 months); median survival after second metastatic resection was 16.3 months (range 2.0-94.5 months; Table 6). 
Table 3 Neoadjuvant/adjuvant treatment regime in 17 patients with R0 resected colorectal liver and lung metastases

\begin{tabular}{lllll}
\hline Primary resection & & & \\
\hline Year & Neoadjuvant Tx & Adjuvant Tx & Tx after 1. Met. & Tx after 2. Met. \\
\hline 1990 & - & 5-FU/Leucovorin & Liver perfusion (Mitomycin C) & FOLFOX \\
1994 & - & 5-FU/Leucovorin & R thoracic vertebrae & Tomodex \\
1995 & - & - & mc Antibody & Cap. \\
1997 & - & mc Antibody & 5-FU & mc Antibody \\
2000 & - & 5-FU (POON) & (intolerance) & (complication) \\
2001 & - & FOLFIRI & FOLFIRI & R/FOLFOX 4 \\
2002 & - & - & - & FOLFOX 4 \\
2002 & - & 5-FU (Ardalan) & Cap. & Cap./Oxaliplatin \\
2002 & R/5-FU & - & Tx refused by patient & Tx refused by patient \\
2003 & - & - & FOLFIRI/Bevacizumab & FUFOX/Bevacizumab \\
2003 & R/5-FU & 5-FU & FOLFOX 4 & FOLFOX 4 \\
2003 & - & R/FOLFOX & F-FU/IT/Cetuximab & Erbitux/Oxaliplatin/Cap. \\
2004 & - & R/5-FU & FOLFIRI & FOLFIRI/Cetuximab \\
2004 & - & FOLFIRI/Bevacizumab & 5-FU/Oxaliplatin & Bevacizumab \\
2006 & - & F-FU/IT/ Bevacizumab & - & FOLFOX/Cetuximab \\
2006 & - & FOLFOX & Cap. & FOLFOX/Cetuximab \\
2006 & R/5-FU & & & FOLFIRI/Bevacizumab \\
\hline
\end{tabular}

$T x$ treatment, $R$ radiotherapy, 5-FU 5-fluoruracil, Cap. capecitabine, IT irinotecan, FOLFOX 5-fluoruracil, oxaliplatin, leucovorin, FOLFIRI 5fluoruracil, leucovorin, irinotecan, mc Antibody 17-1A monoclonal antibody (Panorex ${ }^{\mathbb{B}}$ )

There was no difference in OS for patients with synchronous versus metachronous liver and lung metastases $(p=0.6)$.

Risk analysis was performed using univariate analysis (chi-square). Table 7 shows survival rates as a function of age, DFI, gender, nodal status, grading and stage of disease: In our data, stage of disease, age and DFI were significant prognostic factors. Multivariate analysis (Cox regression) for $>18$ months DFI, stage of disease (III/UICC) and age
( $<70$ years) was performed: All of them were found to be independent prognostic factors for an improved overall survival (Table 8).

\section{Discussion}

Surgical treatment of hepatic metastases of CRC has been reported with a 5-year survival from $30 \%$ to $39 \%$ [4, 6, 15,
Table 4 Mode of resection of liver and lung metastases

\begin{tabular}{|c|c|c|c|}
\hline & Mode of resection & $(n)$ & Total number of resected metastases $(n)$ \\
\hline \multicolumn{4}{|c|}{ First metastasectomy } \\
\hline Lung & Wedge resection & & \\
\hline \multirow[t]{5}{*}{ Liver } & Wedge resection & 1 & 2 \\
\hline & Segmentectomy & 10 & 15 \\
\hline & Hemihepatectomy & 6 & 6 \\
\hline & Thermal ablation & 2 & 2 \\
\hline & Radiofrequency ablation & 2 & 2 \\
\hline \multicolumn{4}{|c|}{ Second metastasectomy } \\
\hline \multirow[t]{4}{*}{ Lung } & Wedge resection & 10 & 28 \\
\hline & Laser resection & 2 & 21 \\
\hline & Segmentectomy & 3 & 11 \\
\hline & Lobectomy & 1 & 5 \\
\hline \multirow[t]{2}{*}{ Liver } & Hemihepatectomy & 1 & 10 \\
\hline & Segmentectomy & 2 & 3 \\
\hline
\end{tabular}




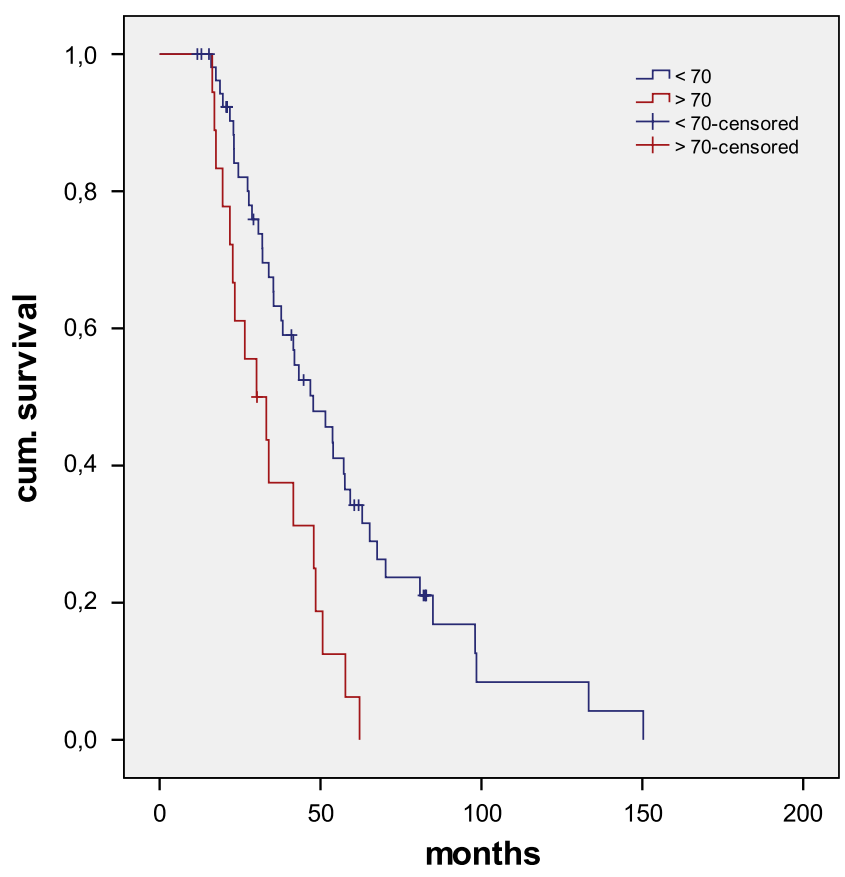

Fig. 3 Overall survival (Kaplan-Meier) of patients $<70$ years (blue line) versus $>70$ years (red line)

16], whilst the reported 5-year survival in patients with pulmonary metastasectomy from CRC ranges from $30 \%$ to $60 \%$ [7-9, 17-20]. In our series, the results of patients with both resection of hepatic and pulmonary metastases were in that range (55\%). Yano et al. reported a 5-year survival of $68.6 \%$ in seven patients with both hepatic and pulmonary resection, which underlines the necessity of an aggressive surgical approach in these patients [21]. Other authors reported similar results [10-12, 22-25]. Our results with a median survival of 98 months and a 5-year survival of 55\% confirm this approach. The apparently improved survival rates for patients with resected hepatic and pulmonary metastases compared to either isolated hepatic or pulmonary metastases are presumably caused by a strict selection of patients and a small number of patients. Multiloculary metastatic disease provides no benefit of survival by nature. Many patients decline metastasectomy following the initial

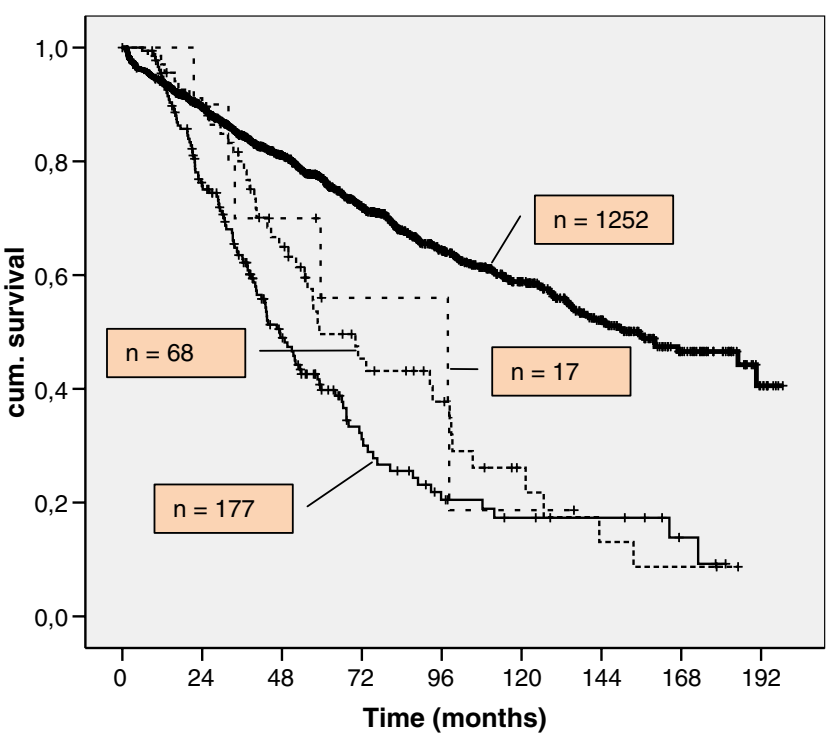

Fig. 4 Overall survival calculated by Kaplan-Meier method for all patients with staged hepatic and pulmonary metastasectomy in colorectal cancer. Thick line, colorectal cancer group; thin line, resected liver metastases; dashed line, resected lung metastases; dotted line, $\mathrm{R} 0$ resected both liver and lung metastases

cancer resection for personal reasons. Furthermore, the metastasectomy cannot be offered to a number of patients due to reduced general condition. In our opinion, a lowering of selection criteria will most likely lead to an increase of resections and an assimilation of the survival rates for patients with isolated liver or lung metastases and patients with both liver and lung metastases. Surgical metastasectomy should always be performed if the primary tumour is under control and if the patient has the prospect of complete resection, even in case of a multilocular clinical manifestation. The presence of a systemic spread of disease such as peritoneal carcinosis, pleural carcinosis, hepatic or celiac metastatic lymph nodes is still a contraindication to surgical metastasectomy, whilst the presence of even multiple lung or liver metastases is not a contradiction to surgical treatment. Patients with a solitary metachronous metastases show a benefit in survival [26]. But also simultaneous metastases do not preclude patients from a

Table 5 Survival rates after primary resection

\begin{tabular}{llcccc}
\hline & & 3years (\%) & 5years (\%) & 10years (\%) & Overall survival median (months) \\
\hline Colorectal cancer & 1,252 & 85 & 77 & 77 & 155 \\
Pulmonary metastases & 68 & 78 & 50 & 26 & 59 \\
Hepatic metastases & 177 & 63 & 40 & 17 & 47 \\
Total & 1,497 & & & & \\
Both liver and lung & 73 & & & & \\
$\quad$ Surgical treatment (R0) & 17 & 77 & 55 & 18 & 35 \\
Non-surgical/partly surgical treatment & 56 & 48 & 19 & 2 \\
\hline
\end{tabular}


Table 6 Survival of patients undergoing hepatic and pulmonary resection for colorectal metastases

\begin{tabular}{lcccc}
\hline Patient no. & Survival (months) & & & \\
\cline { 2 - 5 } & Primary tumour resection & First metastasectomy & Second metastasectomy & Status \\
\hline 1 & 34 & 16 & 13 & DOD \\
2 & 60 & 49 & 30 & AWD \\
$3^{\mathrm{a}}$ & 98 & 98 & 54 & DOD \\
4 & 22 & 10 & 2 & DOD \\
5 & 98 & 26 & 16 & DOD \\
$6^{\mathrm{b}}$ & 59 & 59 & 28 & AWD \\
$7^{\mathrm{b}}$ & 54 & 54 & 50 & AWD \\
8 & 32 & 15 & 6 & DOD \\
9 & 136 & 117 & 95 & AWD \\
$10^{\mathrm{b}}$ & 48 & 48 & 15 & DOD \\
$11^{\mathrm{b}}$ & 41 & 41 & 5 & NED \\
12 & 45 & 21 & NED \\
13 & 29 & 18 & NED \\
14 & 21 & 13 & 9 & NED \\
15 & 21 & 17 & 8 & NED \\
16 & 62 & 17 & AWD \\
17 & 28 & 20 & DOD \\
\hline & & & 10 & 10 \\
\hline
\end{tabular}

Table 7 Risk factors for overall survival in patients with colorectal liver and lung metastases $(n=73)$

Predictors for overall survival with reference to primary resection (univariate analysis)

\begin{tabular}{|c|c|c|c|c|c|}
\hline & & & Mean interval $\pm \mathrm{SD}$ & Median interval (months) $\pm \mathrm{SD}$ & $p$ value \\
\hline \multirow[t]{6}{*}{ Age } & $<65$ years & 46 & $58.7 \pm 6.1$ & $51.5 \pm 5.1$ & \\
\hline & $>65$ years & 27 & $37.1 \pm 3.4$ & $33.1 \pm 3.1$ & 0.06 \\
\hline & $<70$ years & 55 & $56.7 \pm 5.5$ & $47.7 \pm 6.6$ & \\
\hline & $>70$ years & 18 & $34.3 \pm 3.6$ & $30.1 \pm 6.7$ & 0.02 \\
\hline & $<75$ years & 66 & $52.8 \pm 4.7$ & $43.3 \pm 6.5$ & \\
\hline & $>75$ years & 7 & $33.1 \pm 5.1$ & $33.1 \pm 8.7$ & 0.032 \\
\hline \multirow[t]{2}{*}{ Gender } & Male & & $53.7 \pm 5.5$ & $43.2 \pm 7.2$ & \\
\hline & Female & & $44.9 \pm 5.6$ & $41.5 \pm 5.4$ & 0.29 \\
\hline \multirow[t]{4}{*}{ DFI } & $<18$ months & 48 & $39.5 \pm 3.5$ & $33.9 \pm 2.4$ & \\
\hline & $>18$ months & 25 & $68.2 \pm 7.9$ & $62.1 \pm 11.1$ & 0.001 \\
\hline & $<24$ months & 60 & $44.2 \pm 4.2$ & $35.3 \pm 4.7$ & \\
\hline & $>24$ months & 13 & $76.1 \pm 10.5$ & $67.5 \pm 8.4$ & 0.01 \\
\hline \multirow[t]{2}{*}{ Nodal status } & Positive & 48 & $48.6 \pm 4.7$ & $54.5 \pm 8.6$ & \\
\hline & Negative & 25 & $43.3 \pm 8.5$ & $41.5 \pm 2.8$ & 0.618 \\
\hline \multirow[t]{2}{*}{ Grading } & G2 & & $49.7 \pm 5.2$ & $41.5 \pm 7.1$ & 0.8 \\
\hline & G3 & & $53.3 \pm 7.3$ & $43.3 \pm 11.1$ & 0.7 \\
\hline \multirow[t]{4}{*}{ Dukes } & A & 6 & $67.3 \pm 19.4$ & $38.3 \pm 7.8$ & 0.252 \\
\hline & B & 17 & $44.4 \pm 4.5$ & $41.5 \pm 6.0$ & 0.638 \\
\hline & $\mathrm{C}$ & 34 & $46.8 \pm 5.7$ & $35.4 \pm 6.7$ & 0.362 \\
\hline & $\mathrm{D}$ & 16 & $54.7 \pm 8.9$ & $51.5 \pm 13.8$ & 0.525 \\
\hline \multirow[t]{4}{*}{ T-stage } & 1 & 2 & $22.4 \pm 6.4$ & 16.0 & 0.006 \\
\hline & 2 & 10 & $62.9 \pm 18.1$ & $72.8 \pm 15.4$ & 0.063 \\
\hline & 3 & 53 & $49.4 \pm 4.7$ & $41.9 \pm 6.6$ & 0.603 \\
\hline & 4 & 8 & $39.5 \pm 8.1$ & $31.9 \pm 2.4$ & 0.274 \\
\hline
\end{tabular}


Table 8 Risk factors for overall survival in patients with colorectal liver and lung metastases $(n=73)$

$D F I$ disease-free interval, $T 2$ stage III: TNM classification of malignant tumours [13]
Predictors for overall survival with reference to primary resection (multivariate analysis)

\begin{tabular}{|c|c|c|c|c|}
\hline & & $95 \% \mathrm{CI}$ & Mean interval (months) \pm SD & $p$ value \\
\hline DFI & $>18$ months & $02.1-0.69$ & $39.3 \pm 3.5$ & 0.001 \\
\hline T-stage & $\mathrm{T} 2$ & $0.02-0.38$ & $72.8 \pm 15.4$ & 0.05 \\
\hline Age & $<70$ years & $1.5-5.5$ & $56.7 \pm 5.5$ & 0.001 \\
\hline \multicolumn{2}{|c|}{ Stage III (Dukes C) } & $0.2-0.68$ & $46.8 \pm 5.7$ & 0.001 \\
\hline Age & $<75$ years & $1.62-7.85$ & $52.8 \pm 4.7$ & 0.062 \\
\hline
\end{tabular}

possible curative resection, and the survival rates in patients with simultaneous metastases are reported with an equal morbidity and outcome as in patients with metachronous metastases [27, 28]. Bilateral or multiple pulmonary metastases or bilateral hepatic lesions are generally accepted for surgical resection when curative resection is possible. Kobayashi et al. reported a significant difference in the cumulative survival for patients with a solitary pulmonary metastasis versus multiple metastases, whereas the number or resected hepatic lesions did not seem to influence outcome [29].

In the current study, patients with $a$ DFI of more than 18 months had a significant impact on OS versus patients with a DFI $<18$ months. Sato and colleagues reported similar results in patients with isolated liver metastases of CRC. A prolonged DFI was one of the most important factors for OS [30, 31]. Other prognostic variables such as CEA level or number of lesions are also known to affect survival, but none of them is generally accepted to be an absolute contraindication for surgical resection. Headrick et al. [32] reported the presence of lymph node metastases within the chest as one possible contraindication. They identified four patients in their series with positive thoracic lymph nodes who demonstrated a short DFI and a limited survival. These results were trend-setting but not statistically significant.

The surgical approach was also discussed with regards to affecting survival. For primary tumour resection, we performed a standard laparotomy in 15 patients; in two patients, we performed a laparoscopic-assisted colectomy. The method of resection of hepatic and pulmonary metastases in our patients did not influence the outcome. We used an anterolateral thoracotomy as the standard approach in most of our patients. In those patients with a single pulmonary lesion, we used video-assisted thoracoscopic surgery. One patient with multiple lesions $(n=20)$ was treated with laser ablation at the time of thoracotomy. The standard approach for hepatic metastases was a median laparotomy in all patients. The surgical approach did not appear to influence patient outcome. Other authors have reported similar results $[33,34]$.
For patients with stage III colon cancer, adjuvant chemotherapy is widely accepted, whereas in stage II disease, no significant benefit is reported $[35,36]$. Adjuvant chemo-radiotherapy for rectal cancer is indicated in stage II or stage III and in patients where radical (R0) resection could not have been reached [37]. Whilst the value of adjuvant therapy of CRC after initial resection is clear, the value of adjuvant therapy after metastasectomy of CRC is not clarified at all. In four international studies, recruiting more than 3,300 patients with resected hepatic metastases of CRC, no significant benefit of an adjuvant therapy after metastasectomy could be detected. The 5-year survival rate after resection of hepatic metastases of CRC was 28-39\% irrespective of any adjuvant therapy [38, 39]. In the world literature, there is no evidence of a prolonged survival for adjuvant chemotherapy following pulmonary metastasectomy of CRC [40]. Adjuvant chemotherapy after lung resection is therefore not recommended as a standardised therapy should only take place within controlled studies. Patients treated with adjuvant chemotherapy both after primary resection and metastasectomy had a mean survival of 76.6 months, whilst patients without adjuvant therapy achieved a mean survival of 58.7 months. In our series, the OS for patients with adjuvant chemotherapy after metastasectomy was not significantly improved. Besides, a substantial comparison of the (neo)-adjuvant therapy is neither possible nor meaningful due to the long investigation period (18 years). New chemotherapeutic substances, changing application doses, modified therapy patterns or combination therapies do not permit a comparative conclusion. Repeated metastasectomy for recurrent hepatic or pulmonary metastases has been carried out with no increase in either morbidity or mortality. Repeat metastasectomy by laparotomy or thoracotomy will be offered to any selected patient who can tolerate further resection.

Due to its nature, this retrospective study cannot provide evidence for an advantage of surgical treatment over nonsurgical treatment in multiloculary metastatic colorectal cancer. Furthermore, the patient population is limited by high selection. However, the excellent survival rates for selected patients achieved by aggressive surgical therapy 
adduce empirical evidence bearing comparison with nonsurgical treatment. But a prospective study comparing surgical treatment of metastatic CRC versus non-surgical treatment is ethically not feasible since-according to oncological guidelines-all patients with resectable liver or lung metastases of CRC (as the first metastases) should be resected. Lung or liver resection is still the only curative treatment for selected patients with metastatic CRC. The long-term survival in our selected group of patients with both resected liver and lung metastases from CRC is comparable to solitary liver or lung metastases. From a surgical point of view, every attempt must be made to increase the availability of any liver or lung resection [41].

Today, the treatment of metastatic colorectal cancer should be performed in a multidisciplinary way, including surgeons, medical oncologists and radiotherapists.

Surgical treatment of even multiple hepatic and pulmonary metastases of colorectal cancer results in significantly increased survival time compared with patients without a surgical approach. In association with new effective chemotherapies, including immunoglobulin monoclonal antibodies, even long-term survival can be achieved.

\section{Conclusion}

Patients with synchronous or metachronous hepatic and pulmonary metastases of colorectal carcinoma should always be considered for a possible surgical resection as it offers a valid therapeutic opportunity with excellent survival rates. An aggressive surgical approach in a specialised centre is safe with low morbidity and low mortality and offers an excellent chance for long-term survival. Overall survival for surgically treated selected patients with both hepatic and pulmonary metastases from CRC is comparable to hepatic or pulmonary metastasectomy.

Open Access This article is distributed under the terms of the Creative Commons Attribution Noncommercial License which permits any noncommercial use, distribution, and reproduction in any medium, provided the original author(s) and source are credited.

\section{References}

1. August DA, Ottow RT, Sugarbaker PH (1984) Clinical perspectives on human colorectal cancer metastases. Cancer Metastasis Rev 3:303-324

2. McCormack PM, Attiyeh FF (1979) Resected pulmonary metastases from colorectal cancer. Dis Colon Rectum 22:553-556

3. Galandiuk S, Wieand HS, Moertel CG, Cha SS, Fitzgibbons RJ, Pemberton JH et al (1992) Patterns of recurrence after curative resection of carcinoma of the colon and rectum. Surg Gynecol Obstet 174:27-32

4. Lehnert T, Knaebel HP, Duck M, Bulzebruck H, Herfarth C (1999) Sequential hepatic and pulmonary resections for metastastic colorectal cancer. Br J Surg 86(2):241-243

5. Poon MA, O'Connel MJ, Moertel CG, Wieand HS, Cullinan SA, Lk E et al (1989) Biochemical modulation of fluororuracil: evidence of significant improvement of survival and quality of life in patients with advanced colorectal carcinoma. J Clin Oncol 7:1407-1414

6. Scheele J, Altendorf-Hofmann A (1999) Resection of colorectal liver metatases. Langenbecks Arch Surg 384(4):313-327

7. Girard P, Ducreux M, Baldeyrou P, Rougier P, Le Chevalier T, Bougaran J, Lasser P, Gayet B, Ruffié P, Grunenwald D (1996) Surgery for lung metastases from colorectal cancer: analysis of prognostic factors. J Clin Oncol 14(7):2047-2053

8. McAfee MK, Allen MS, Trastek VF, Ilstrup DM, Deschamps C, Pairolero PC (1992) Colorectal lung metastases: results of surgical excision. Ann Thorac Surg 53:780-786

9. Nordlinger B, Quilichini MA, Parc R, Hannoun L, Delva E, Huguet C (1987) Hepatic resection for colorectal liver metastases: influence on survival of preoperative factors and surgery for recurrences in 80 patients. Ann Surg 205:256-263

10. Yano TY, Hara N, Ichinose Y, Yokohama H, Miura T, Ohta M (1993) Results of pulmonary resection of metastatic colorectal cancer and its application. J Thorac Cardiovasc Surg 106:875-879

11. Gough DB, Donohue JH, Trastek VA, Nagorney DM (1994) Resection for hepatic and pulmonary metastases in patients with colorectal cancer. Br J Surg 81:94-96

12. Minnard E, Fong Y, Weigel T, Fortner J, Blumgart L, Burt M (1996) Surgical resection for hepatic and pulmonary colorectal metastases. Surg Oncol 15:552

13. Hermanek P, Sobin LH (eds) (1992) UICC TNM classification of malignant tumors, 4th edn, 2nd revision. Springer, Berlin

14. Kaplan EL, Meier P (1958) Nonparametric estimation from incomplete observations. J Am Stat Assoc 53:457-481

15. Bramhall SR, Gur U, Coldham C, Gunson BK, Mayer AD, McMaster P, Candinas D, Buckels JA, Mirza DF (2003) Liver resection for colorectal metastases. Ann R Coll Surg Engl 85 (5):334-339

16. Scheele J, Stangl R, Altendorf-Hofmann A, Paul M (1995) Resection of colorectal liver metastases. World J Surg 19:59-71

17. Inoue $M$, Ohta $M$, Iuchi $K$, Matsamura A, Ideguchi K, Yasumitsu T, Nakagawa K, Fukuhara K, Maeda H, Takeda S, Minami M, Ohno Y, Matsuda H, Thoracic Surgery Study Group of Osaka University (2004) Benefits of surgery for patients with pulmonary metastases from colorectal carcinoma. Ann Thorac Surg 78 (1):238-244

18. Saito Y, Omiya H, Kohno K, Kobayashi T, Itoi K, Teramachi M, Sasaki M, Suzuki H, Takao H, Nakade M (2002) Pulmonary metastasectomy for 165 patients with colorectal carcinoma: a prognostic assessment. J Thorac Cardiovasc Surg 124(5):1007-1013

19. Pfannschmidt J, Muley T, Hoffmann H, Dienemann H (2003) Prognostic factors and survival after complete resection of pulmonary metastases from colorectal carcinoma: experiences in 167 patients. J Thorac Cardiovasc Surg 126(3):732-739

20. Pfannschmidt J, Dienemann H, Hoffmann H (2007) Surgical resection of pulmonary metastases from colorectal cancer: a systemic review of published series. Ann Thorac Surg 84 (1):324-338

21. Avital I, DeMatteo R (2006) Combined resection of liver and lung metastases for colorectal cancer. Thorac Surg Clin 16(2):145-155

22. Ambiru S, Miyazaki M, Ito H, Nakagawa K, Shimizu H, Kato A, Nakamura S, Omoto H, Nakajima N (1998) Resection of hepatic and pulmonary metastases in patients with colorectal carcinoma. Cancer 82(2):274-278 
23. Hamy A, Baron O, Bennouna J, Roussel JC, Paineau J, Douillard JY (2001) Resection of hepatic and pulmonary metastases in patients with colorectal cancer. Am J Clin Oncol 24(6):607-609

24. Mineo TC, Ambrogi V, Tonini G, Bollero P, Roselli M, Mineo D, Nofroni I (2003) Longterm results after resection of simultaneous and sequential lung and liver metastases from colorectal carcinoma. J Am Coll Surg 197(3):386-391

25. Regnard JF, Grunenwald D, Spaggiari L, Girard P, Elias D, Ducreux M, Baldeyrou P, Levasseur P (1998) Surgical treatment of hepatic and pulmonary metastases from colorectal cancers. Ann Thorac Surg 66(1):214-218

26. Robinson BJ, Rice TW, Strong SA, Rybicki LA, Blackstone EH (1999) Is resection of pulmonary and hepatic metastases warranted in patients with colorectal cancer? J Thorac Cardiovasc Surg 117(1):66-75

27. Shah SA, Haddad R, Al-Sukhni W, Kim RD, Greig PD, Grant DR, Taylor BR, Langer B, Gallinger S, Wei AC (2006) Surgical resection of hepatic and pulmonary metastases from colorectal carcinoma. J Am Coll Surg 202(3):468-475

28. Vogt P, Raab R, Ringe B, Pichlmayr R (1991) Resection of synchronous liver metastases from colorectal cancer. World J Surg 15(1):62-7

29. Kobayashi K, Kawamura M, Ishihara T (1999) Surgical treatment for both pulmonary and hepatic metastases from colorectal cancer. J Thorac Cardiovasc Surg 118(6):1090-1096

30. Sato T, Konishi K, Yabushita K, Nojima N, Kimura H, Meada K, Tsuji M, Miwa A (1998) The time interval between primary colorectal carcinoma resection to occurrence of liver metastases is the most important factor for hepatic resection. Analysis of total course following primary resection of colorectal cancer. Int Surg 83(4):340-342

31. Yedibela S, Klein P, Feuchter K, Hoffmann M, Meyer T, Papadopoulos T, Göhl J, Hohenberger W (2006) Surgical management of pulmonary metastases from colorectal cancer in 153 patients. Ann Surg Oncol 13(11):1538-1544

32. Headrick JR, Miller DL, Nagorney DM, Allen MS, Deschamps C, Trastek VF, Pairolero PC (2001) Surgical treatment of hepatic and pulmonary metastases from colon cancer. Ann Thorac Surg 71 (3):975
33. Reddy RH, Kumar B, Shah R, Mirsadraee S, Papagiannopoulos K, Lodge P, Thorpe JA (2004) Staged pulmonary and hepatic metastasectomy in colorectal cancer-is it worth it? Eur J Cardiothorac Surg 25(2):151-154

34. Ike H, Shimada H, Togo S, Yamaguchi S, Ichikawa Y, Tanaka K (2002) Sequential resection of lung metastases following partial hepatectomy for colorectal cancer. Br J Surg 89(9):1164-1168

35. Benson AB 3 rd, Schrag D, Somerfield MR, Cohen AM, Figueredo AT, Flynn PJ, Krzyzanowska MK, Maroun J, McAllister P, Van Cutsem E, Brouwers M, Charette M, Haller DG (2004) American Society of Clinical Oncology recommendations on adjuvant chemotherapy for stage II colon cancer. J Clin Oncol 22 (16):3408-3419

36. O'Connell MJ, Mailliard JA, Kahn MJ, Macdonald JS, Haller DG, Mayer RJ, Wieand HS (1997) Controlled trial of flourouracil and low-dose leucovorin given for 6 months as postoperative adjuvant therapy for colon cancer. J Clin Oncol 15(1):246-250

37. Kim BITK et al. (2007) Randomized trial of postoperative adjuvant therapy in stage II and III rectal cancer to define the optimal sequence of chemotherapy and radiotherapy: a final report. ASCO Annual Meeting Proceedings. J Clin Oncol 25(no. 18S):4050

38. Fong Y, Fortner J, Sun RL, Brennan MF, Blumgart LH (1999) Clinical score for predicting recurrence after hepatic resection for metastatic colorectal cancer: analysis of 1001 consecutive cases. Ann Surg 230(3):309-318, discussion 318-321

39. Kato T, Yasui K, Hirai T, Kanemitsu Y, Mori T, Sugihara K, Mochizuki H, Yamamoto J (2003) Therapeutic results for hepatic metastasis of colorectal cancer with special reference to effectiveness of hepatectomy: analysis of prognostic factors for 763 cases recorded at 18 institutions. Dis Colon Rectum 46(10 Suppl):S22-S31

40. Rau B, Kandioler D, Stamatis G (2008) Chirurgische Onkologie: Strategien und Standards für die Praxis (edited by Gnant M, Schlag PM). Springer, Berlin

41. Poston GJ, Adam R, Alberts S, Curley S, Figueras J, Haller D, Kunstlinger F, Mentha G, Nordlinger B, Patt Y, Primrose J, Roh M, Rougier P, Ruers T, Schmoll HJ, Valls C, Vauthey NJ, Cornelis M, Kahan JP (2005) Oncosurg: a strategy for improving respectability with curative intent in metastatic colorectal cancer. J Clin Oncol 23(28):7125-7134 